\title{
Sedentary Behavior in Preschoolers: How Many Days of Accelerometer Monitoring Is Needed?
}

\section{Wonwoo Byun ${ }^{1, *}$, Michael W. Beets ${ }^{2}$ and Russell R. Pate ${ }^{2}$}

1 Department of Health, Nutrition, and Exercise Sciences, Department of Public Health, North Dakota State University, Fargo, ND 58108, USA

2 Department of Exercise Science, Arnold School of Public Health, University of South Carolina, Columbia, SC 29208, USA; E-Mails: beets@mailbox.sc.edu (M.W.B.); rpate@mailbox.sc.edu (R.R.P.)

* Author to whom correspondence should be addressed; E-Mail: w.byun@ndsu.edu; Tel.: +1-701-231-6738; Fax: +1-701-231-8872.

Academic Editor: Paul B. Tchounwou

Received: 7 August 2015 / Accepted: 10 October 2015 / Published: 20 October 2015

\begin{abstract}
The reliability of accelerometry for measuring sedentary behavior in preschoolers has not been determined, thus we determined how many days of accelerometry monitoring are necessary to reliably estimate daily time spent in sedentary behavior in preschoolers. In total, 191 and 150 preschoolers (three to five years) wore ActiGraph accelerometers (15-s epoch) during the in-school ( $\geq 4$ days) and the total-day ( $\geq 6$ days) period respectively. Accelerometry data were summarized as time spent in sedentary behavior $(\mathrm{min} / \mathrm{h})$ using three different cutpoints developed for preschool-age children $(<37.5,<200$, and $<373$ counts/15 s). The intraclass correlations (ICCs) and Spearman-Brown prophecy formula were used to estimate the reliability of accelerometer for measuring sedentary behavior. Across different cutpoints, the ICCs ranged from 0.81 to 0.92 for in-school sedentary behavior, and from 0.75 to 0.81 for total-day sedentary behavior, respectively. To achieve an ICC of $\geq 0.8$, two to four days or six to nine days of monitoring were needed for in-school sedentary behavior and total-day sedentary behavior, respectively. These findings provide important guidance for future research on sedentary behavior in preschool children using accelerometry. Understanding the reliability of accelerometry will facilitate the conduct of research designed to inform policies and practices aimed at reducing sedentary behavior in preschool children.
\end{abstract}


Keywords: reliability; activity monitor; children; preschool; sedentary

\section{Introduction}

Childhood obesity is a significant public health concern because of its long-term detrimental health effects [1-4]. The rapid increase of obesity rates in American children and youth are known to be very difficult to reverse [5]. According to recent data from a representative sample, a third of American children and youth are classified as either overweight or obese [6]. In addition, childhood obesity is associated with numerous adverse health outcomes including type 2 diabetes, insulin resistance, hypertension, dyslipidemia, fatty liver disease, obstructive sleep apnea, and psychosocial difficulties in adulthood [7,8]. Given that obesity tracks into adulthood $[9,10]$, efforts to prevent childhood obesity cannot be overemphasized.

Contemporary children spend a significant amount of their waking hours in sedentary behavior and this may result in negative health consequences. Recent studies reported that the majority of North American children engage in sedentary behavior more than the recommended levels [11-16], which are $\leq 2 \mathrm{~h}$ per day of TV watching [17] and $<45 \mathrm{~min}$ per hour of sedentary behavior (equal to $\geq 15$ min per hour of total physical activity) in childcare centers [18]. Accumulating evidence has recently shown that excessive sedentary behavior in childhood is a major contributor for obesity [19-24] and poor metabolic health [25-29], and it also impacts obesity and metabolic health in adulthood [30,31]. Therefore, the improvement of assessment methods for monitoring and reducing sedentary behavior is an important public health priority.

Accelerometry has been considered the method of choice for objective measurement of physical activity and sedentary behavior in children [32,33]. Its popularity is primarily due to its unobtrusiveness, light weight, small size, and ability to measure intensity, duration, and frequency of activities that children engaged in. In addition, accelerometery-derived activity data are less likely to be biased by recall or researcher bias. A recent study determined the reliability of measures of sedentary behavior in six- to eight-year-old elementary school children, and found that five days of accelerometry monitoring was necessary to reliably measure sedentary behavior [34]. However, the application of accelerometry in preschool-age (three- to five-year-old) children is relatively new, and little research has examined the reliability of accelerometry for measuring sedentary behavior among this population.

Using an Intraclass Correlation Coefficient (ICC) of $\geq 0.8$ as the standard for acceptable reliability, previous studies determined the reliability of accelerometery-derived physical activity (PA) in children (aged 3-17 years), and reported that the recommended number of days of accelerometry monitoring to reliably measure moderate-to-vigorous PA varies from 4 to 10 days [35-38]. To our knowledge, however, no study has assessed the reliability of accelerometry-derived sedentary behavior in three- to five-year-old preschool children.

In addition to reliability, an important methodological issue in measuring sedentary behavior via accelerometry is the choice of cutpoints. Several cutpoints for preschool-age children have been used in previous studies, including $<26$ counts/15 s [39], <37.5 counts/15 s [40], <200 counts/15 s [40], $<275$ counts/15 s [32], $<302$ counts/15 s (for 4 years), [41] and $<373$ counts/15 s [42]. Depending on the 
cutpoint, the estimated time spent in accelerometry-derived sedentary behavior varies markedly (e.g., $343.2 \mathrm{~min} /$ day to $617.6 \mathrm{~min} /$ day) [42]. This suggests that the reliability of accelerometry-derived sedentary behavior differs when different cutpoints are used. Therefore, the purpose of this study was to determine how many days of accelerometry monitoring are necessary to reliably estimate daily time spent in sedentary behavior in preschool children when applying three different accelerometry cutpoints.

\section{Experimental Section}

\subsection{Study Design}

A cross-sectional study design was employed, and analyses were performed using data from the Children's Activity and Movement in Preschool Study (CHAMPS). Details regarding the design of CHAMPS are available elsewhere [43]. Briefly, activity data were collected over 8-10 consecutive days in a sample of preschool children. Trained data collectors recorded preschool arrival and departure times for each child, so that each child's daily activity data can be summarized as in-school sedentary behavior monitored during school hours, and total-day sedentary behavior monitored during and after school hours. For the analyses in the current study, we identified the subsets of the overall sample $(N=331)$ according to the activity monitored (in-school and total day) as follows: children who had at least 4 valid days (weekdays) of in-school sedentary behavior data $(N=191)$, or at least 6 valid days (including weekend days) of total-day sedentary behavior data $(N=150)$, respectively. A total of 139 children were identified in both subsamples (overlap sample).

\subsection{Participants}

The participants in this study were 3- to 5-year-olds preschool children. Using a stratified random sampling procedure, a total of 22 preschools (11 commercial, 7 religious, and 4 Head Start) agreed to participate in CHAMPS. The 22 preschools were recruited from the greater Columbia, South Carolina, USA, an area that includes a wide range of ethnic and socioeconomic backgrounds. The number of participants per preschool ranged from 14 to 33 children. Written informed consent was obtained from children's parents or guardians prior to collection of data. The study was approved by the Institutional Review Board at the University of South Carolina.

\subsection{Sedentary Behavior}

Sedentary behavior was measured using ActiGraph accelerometers (ActiGraph model 7164, Shalimar, FL, USA). Accelerometers were initialized to save data in 15-s intervals (epochs) in order to more effectively capture the spontaneous movement of 3- to 5-year-old children. Parents were instructed to help their child to wear the accelerometers on an elastic belt on the right hip (anterior to the iliac crest). Parents received information about the monitor and instructions for helping their child wear the monitor over a two-week period. Accelerometry data were summarized in terms of activity counts per $15 \mathrm{~s}$ (cts/15 s).

To determine whether the number of days necessary to reliably estimate accelerometry-derived sedentary behavior in preschool children differs by application of selected sets of cutpoints, the count data were reduced using three different activity intensity cutpoints developed specifically for 3- to 5-year old children to categorize each interval as sedentary. These three cutpoints are $<37.5 \mathrm{cts} / 15 \mathrm{~s}$ [40], 
$<200 \mathrm{cts} / 15 \mathrm{~s}$ [40], and $<373 \mathrm{cts} / 15 \mathrm{~s}$ [42]. Cumulative time ( $\mathrm{min} / \mathrm{h})$ spent in sedentary behavior was then calculated using each child's wear time as the divisor. Sixty-minutes of consecutive zeros were considered as non-wear time [13,44-46]. For in-school activity data, children must have attended school for at least $5 \mathrm{~h}$ on that day. Occasional $(\approx 5 \%)$ missing entry and exit times were imputed based on the child's other data (usual times entered on the consent form, entry and exit times on other days, and school average entry and exit times). Days that children were absent from preschool and on which total wear time was $<6 \mathrm{~h}$ or $\geq 18 \mathrm{~h}$ (i.e., monitor malfunction) were excluded from the analysis because those do not represent typical days.

\subsection{Demographic and Anthropometric Characteristics}

Children's age, gender, race/ethnicity, and socioeconomic status were reported by a parent or guardian using a parent survey. Weight was measured to the nearest $0.1 \mathrm{~kg}$ using an electronic scale, and height was measured to the nearest $1 \mathrm{~mm}$ using a stadiometer, after the child had removed shoes and outer clothing. Parent education ( $\leq$ High school, $>$ High school) was measured as a surrogate indicator of socioeconomic status. Body Mass Index (BMI) was calculated $\left(\mathrm{kg} / \mathrm{m}^{2}\right)$ from the averages of both height and weight.

\subsection{Statistical Analysis}

Descriptive statistics (Mean, SD, and percent) were calculated for the subsets of the overall sample according to the activity monitored (in-school and total day). The coefficient of variance $(\mathrm{CoV}=(\mathrm{SD} /$ mean $) \times 100)$ was calculated to describe between-individual variability [47]. A repeated measures analysis of variance (ANOVA) was used to determine if the amount of time spent in sedentary behavior is different across days of the week. Specifically, the difference in sedentary behavior was estimated by the PROC MIXED procedure in SAS, including gender, preschools, and gender $\times$ days of the week as the covariates, and a compound symmetric as the covariance structure. If an overall $F$-test was significant, multiple pairwise comparisons with Tukey adjustment were performed to determine differences in sedentary behavior between days. The LS MEANS statement with the PDIFF option was also included for pairwise comparisons in the PROC MIXED procedure.

The ICC was used to determine the reliability of the accelerometry-derived sedentary behavior and calculated using variance estimates from the two-way repeated ANOVA model and the formula below [48]:

$$
R=\left(M S_{s}-M S_{i}\right) /\left[M S_{s}+\left(K / K^{\prime}-1\right)\left(M S_{i}\right)\right]
$$

where $M S_{s}$ is the mean square subject indicating the between-subject variability, $M S_{i}$ is the mean square interaction indicating variability interaction between the between-subject and within-subject variability, $K$ is the number of days administered, $K$ ' is the number of days for which $\mathrm{R}$ is estimated, and $R$ is the ICC.

The number of days of accelerometry monitoring required to reliably estimate sedentary behavior in preschool children was estimated using the Spearman-Brown prophecy formula below [48]:

$$
\mathrm{r}^{*}{ }_{\mathrm{xx}},=K\left(r_{x x^{\prime}}\right) /\left[1+(K-1)\left(r_{x x^{\prime}}\right)\right]
$$


where $r_{x x}$, is the estimated reliability (ICC) of the test, $\mathrm{r}^{*}{ }_{\mathrm{xx}}$, is the desired reliability (ICC) of the lengthened test, and $K$ is the number of times (days) the length of the test has been increased. More specifically, the ICC of 0.8 was considered as the desired reliability cutoff to determine the minimum number of days necessary to reliably estimate sedentary behavior [49].

The Standard Error of Measurement (SEM) was calculated to examine the precision of measured sedentary behavior from the estimated ICCs. The following formula was used [50]:

$$
S E M=S_{x} \sqrt{\left(1-r_{x x^{\prime}}\right)}
$$

where $S_{x}$ is standard deviation of observed score, and $r_{x x}$, is the estimated reliability (ICC) of the test. For all statistical analyses, the SAS statistical program, version 9.2 (SAS Institute, Cary, NC, USA) was used and the alpha level of 0.05 was considered as statistical significance.

\section{Results}

\subsection{General Characteristics}

Demographic characteristics of the participants and the average time the children wore the accelerometers are shown in Table 1. Approximately half of the children in this study were girls and half were African American. On average, the children wore the accelerometers for a total of $12.1 \mathrm{~h} / \mathrm{day}$ and for $8.4 \mathrm{~h}$ /day while in school. The distribution of age, gender, race, and BMI was not different between two subsets of the overall sample (in-school vs. total-day).

Table 1. Characteristics of Participants by Activity Monitored, Mean (SD) or Percent.

\begin{tabular}{|c|c|c|}
\hline \multirow{2}{*}{ Characteristics } & \multicolumn{2}{|c|}{ Activity Monitored } \\
\hline & In-School $^{a}$ & Total-Day $^{b}$ \\
\hline $\mathrm{N}$ & 191 & 150 \\
\hline Age (years) & $4.1(0.7)$ & $4.1(0.6)$ \\
\hline BMI $\left(\mathrm{kg} / \mathrm{m}^{2}\right)$ & $16.4(2.3)$ & $16.3(1.9)$ \\
\hline \multicolumn{3}{|l|}{ Gender (\%) } \\
\hline Boys & 49.7 & 48.7 \\
\hline Girls & 50.3 & 51.3 \\
\hline \multicolumn{3}{|l|}{ Race $(\%)$} \\
\hline African American & 45.6 & 48.0 \\
\hline White & 42.7 & 39.3 \\
\hline Other & 11.5 & 12.7 \\
\hline \multicolumn{3}{|l|}{ Wear Time ${ }^{\mathbf{c}}$} \\
\hline Number of Days & $4.6(0.5)$ & $6.6(0.5)$ \\
\hline Hours per Day & $8.4(1.4)$ & $12.1(2.6)$ \\
\hline
\end{tabular}




\subsection{Variability of Sedentary Behavior}

The univariate analyses showed that the average time spent in sedentary behavior varied from 32 $\mathrm{min} / \mathrm{h}$ to $51 \mathrm{~min} / \mathrm{h}$ for both in-school and total-day depending upon the cutpoints used (Table 2). Regardless of cutpoints, $\mathrm{CoV}$ was greater for in-school sedentary behavior than total-day sedentary behavior, which indicates greater between-individual variability for in-school sedentary behavior compared to total-day sedentary behavior.

Table 2. Minimum, Maximum, Mean (SD), and Coefficient of Variance of Sedentary Behavior.

\begin{tabular}{|c|c|c|c|c|c|}
\hline \multirow{2}{*}{ Cutpoints } & \multirow{2}{*}{ Activity Monitored } & \multicolumn{3}{|c|}{ Sedentary Behavior $(\mathrm{min} / \mathrm{h})$} & \multirow{2}{*}{$\operatorname{CoV}(\%$} \\
\hline & & Min & Max & Mean (SD) & \\
\hline \multirow{2}{*}{$<37.5 \mathrm{cts} / 15 \mathrm{~s}$} & In-school & 13.4 & 46.9 & $32.1(6.6)$ & 20.6 \\
\hline & Total-day & 19.6 & 40.0 & $32.3(3.4)$ & 10.7 \\
\hline \multirow{2}{*}{$<200$ cts $/ 15 \mathrm{~s}$} & In-school & 21.2 & 55.8 & $44.5(5.8)$ & 13.1 \\
\hline & Total-day & 33.7 & 51.1 & $45.6(2.8)$ & 6.1 \\
\hline \multirow{2}{*}{$<373 \mathrm{cts} / 15 \mathrm{~s}$} & In-school & 42.1 & 58.1 & $51.2(3.2)$ & 6.3 \\
\hline & Total-day & 41.7 & 55.0 & $51.3(2.2)$ & 4.2 \\
\hline
\end{tabular}

$\mathrm{CoV}$, Coefficient of Variance.

Gender and preschool-adjusted mean differences in sedentary behavior ( $\mathrm{min} / \mathrm{h}$ ) across days of the week are presented in Table 3. There were no significant differences in $\mathrm{min} / \mathrm{h}$ of in-school sedentary behavior across weekdays. For total-day sedentary behavior, however, post-hoc tests showed that preschool children spent less time in sedentary behavior on weekend days compared to weekdays $(P<0.05)$.

\subsection{Reliability of In-School Sedentary Behavior}

The ICCs for in-school sedentary behavior when applying three different accelerometry cutpoints are shown in Table 4. The ICCs were calculated for 1 day, 3 days, and 5 days. Across three different cutpoints, the ICCs ranged from 0.48 to 0.64 , from 0.73 to 0.84 , and from 0.82 to 0.90 for 1 day, 3 days, and 5 days, respectively. The number of days of accelerometry monitoring required to achieve the given levels of ICC ( $\geq 0.7, \geq 0.75, \geq 0.8$, and $\geq 0.9$ ) was calculated for in-school sedentary behavior (Table 4). The lowest number of days needed for the ICC of $\geq 0.8$ was 2 days if used the cutpoint of $<200 \mathrm{cts} / 15 \mathrm{~s}$. Across three different cutpoints, between 2 and 4 days of monitoring was needed to achieve an ICC of $\geq 0.8$. 
Table 3. Accelerometry-derived Time Spent in Sedentary Behavior across Days of the Week, Mean (SE).

\begin{tabular}{|c|c|c|c|c|c|c|}
\hline \multirow{4}{*}{ Day of the Week } & \multicolumn{6}{|c|}{ Sedentary Behavior Cutpoints } \\
\hline & \multicolumn{2}{|c|}{$<37.5 \mathrm{cts} / 15 \mathrm{~s}$} & \multicolumn{2}{|c|}{$<200$ cts $/ 15 \mathrm{~s}$} & \multicolumn{2}{|c|}{$<375$ cts $/ 15$ s } \\
\hline & \multicolumn{2}{|c|}{ Sedentary Behavior $(\mathrm{min} / \mathrm{h})$} & \multicolumn{2}{|c|}{ Sedentary Behavior $(\mathrm{min} / \mathrm{h})$} & \multicolumn{2}{|c|}{ Sedentary Behavior $(\mathrm{min} / \mathrm{h})$} \\
\hline & In-School & Total-Day & In-School & Total-Day & In-School & Total-Day \\
\hline MON & $32.9(0.69)$ & $33.2(0.48)$ & $44.7(0.52)$ & $46.0(0.29)$ & $51.4(0.36)$ & $51.6(0.29)$ \\
\hline TUE & $33.3(0.68)$ & $33.1(0.48)$ & $45.3(0.50)$ & $46.2(0.29)$ & $51.6(0.35)$ & $51.7(0.29)$ \\
\hline WED & $32.5(0.68)$ & $32.7(0.47)$ & $44.9(0.51)$ & $45.8(0.28)$ & $51.5(0.35)$ & $51.5(0.29)$ \\
\hline THU & $33.7(0.67)$ & $33.5(0.47)$ & $45.6(0.51)$ & $46.6(0.28)$ & $51.9(0.35)$ & $52.0(0.29)$ \\
\hline FRI & $32.0(0.71)$ & $32.8(0.48)$ & $44.3(0.53)$ & $45.9(0.29)$ & $51.1(0.37)$ & $51.5(0.30)$ \\
\hline SAT & & $30.4(0.48)$ & & $44.1(0.29)$ & & $50.5(0.30)$ \\
\hline SUN & & $31.4(0.48)$ & & $45.0(0.29)$ & & $51.0(0.29)$ \\
\hline Average & 32.9 & 32.4 & 45.0 & 45.7 & 51.5 & 51.4 \\
\hline$P$ for trend ${ }^{a}$ & 0.19 & $<0.05^{\mathbf{b}}$ & 0.17 & $<0.05^{\text {b }}$ & 0.35 & $<0.05^{\mathbf{b}}$ \\
\hline
\end{tabular}

${ }^{\mathbf{a}}$ Gender and preschool-adjusted repeated measures ANOVA; ${ }^{\mathbf{b}}$ Pairwise comparisons showed that SAT and SUN differ from MON-FRI, $P<0.05$.

Table 4. ICCs, Number of Days to Achieve Desired ICCs, and SEMs According to Three Different Cutpoints.

\begin{tabular}{|c|c|c|c|c|c|c|c|c|c|c|c|c|}
\hline \multirow{2}{*}{$\begin{array}{c}\text { In-School }(N=191) \\
\text { Cutpoints }\end{array}$} & \multicolumn{3}{|c|}{$\operatorname{ICCs}^{\mathrm{a}}$} & \multicolumn{4}{|c|}{$\begin{array}{c}\text { Number of Days for the } \\
\text { Following ICCs } \\
\end{array}$} & \multicolumn{5}{|c|}{ SEMs $^{d}$} \\
\hline & $1 \mathrm{~d}$ & $3 \mathrm{~d}$ & $5 \mathrm{~d}$ & 0.7 & 0.75 & 0.8 & 0.9 & $1 \mathrm{~d}$ & $2 \mathrm{~d}$ & $3 \mathrm{~d}$ & $4 d$ & $5 \mathrm{~d}$ \\
\hline$<37.5 \mathrm{cts} / 15 \mathrm{~s}$ & 0.51 & 0.76 & 0.84 & 2 & 3 & 4 & 9 & 4.6 & 3.7 & 3.2 & 2.9 & 2.6 \\
\hline$<200 \mathrm{cts} / 15 \mathrm{~s}$ & 0.64 & 0.84 & 0.90 & 1 & 2 & 2 & 5 & 3.5 & 2.7 & 2.3 & 2.0 & 1.8 \\
\hline$<373 \mathrm{cts} / 15 \mathrm{~s}$ & 0.48 & 0.73 & 0.82 & 2 & 3 & 4 & 10 & 2.3 & 1.9 & 1.7 & 1.5 & 1.4 \\
\hline Total-Day $(N=150)$ & \multicolumn{3}{|c|}{$\operatorname{ICCs}^{b}$} & \multicolumn{4}{|c|}{$\begin{array}{l}\text { Number of Days for the } \\
\text { Following ICCs } \\
\end{array}$} & \multicolumn{5}{|c|}{ SEMs $^{d}$} \\
\hline Cutpoints & $1 \mathrm{~d}$ & $4 \mathrm{~d}$ & $7 \mathrm{~d}$ & 0.7 & 0.75 & 0.8 & 0.9 & $1 \mathrm{~d}$ & $4 d$ & $6 \mathrm{~d}$ & $7 \mathrm{~d}$ & $9 \mathrm{~d}$ \\
\hline$<37.5 \mathrm{cts} / 15 \mathrm{~s}$ & 0.32 & 0.65 & 0.76 & 5 & 6 & 9 & 19 & 2.8 & 2.0 & 1.8 & 1.7 & 1.5 \\
\hline$<200 \mathrm{cts} / 15 \mathrm{~s}$ & 0.36 & 0.69 & 0.80 & 4 & 5 & 7 & 16 & 2.2 & 1.6 & 1.3 & 1.3 & 1.2 \\
\hline$<373 \mathrm{cts} / 15 \mathrm{~s}$ & 0.38 & 0.71 & 0.81 & 4 & 5 & 6 & 14 & 1.7 & 1.2 & 1.0 & 1.0 & 0.9 \\
\hline
\end{tabular}

${ }^{\mathbf{a}}$ ICCs for the $1 \mathrm{~d}, 3 \mathrm{~d}$, and $5 \mathrm{~d}$ of in-school sedentary behavior; ${ }^{\mathbf{b}}$ ICCs for the $1 \mathrm{~d}, 4 \mathrm{~d}$, and $7 \mathrm{~d}$ of total day sedentary behavior; ${ }^{\mathbf{c}}$ Number of days of monitoring required to achieve the ICCs of $0.7,0.75,0.8$, and $0.9{ }^{;}{ }^{\mathrm{d}}$ The unit of SEMs is $\mathrm{min} / \mathrm{h}$ of sedentary behavior. 


\subsection{Reliability of Total-Day Sedentary Behavior}

The number of days of accelerometry monitoring required to achieve the given levels of ICC $(\geq 0.7$, $\geq 0.75, \geq 0.8$, and $\geq 0.9$ ) was calculated for total day sedentary behavior (Table 4). For total-day sedentary behavior, the ICCs were calculated for 1 day, 4 days, and 7 days. Across three different cutpoints, the ICCs ranged from 0.32 to 0.38 , from 0.65 to 0.71 , and from 0.76 to 0.81 for 1 day, 4 days, and 7 days, respectively. The lowest number of days needed for the ICC of $\geq 0.8$ was 6 days if used the cutpoint of $<373 \mathrm{cts} / 15 \mathrm{~s}$. The number of days of accelerometry monitoring required to achieve an ICC of $\geq 0.8$ was between 6 and 9 days across three different cutpoints.

\subsection{SEMs for In-School and Total-Day Sedentary Behavior}

The SEMs, the degree to which estimates of time spent in sedentary behavior $(\mathrm{min} / \mathrm{h})$ fluctuate as a result of measurement errors, are shown in Table 4. For in-school sedentary behavior, the SEMs were calculated for 1-5 days. Across three different cutpoints, the SEMs ranged from 2.3 to 4.6, from 1.7 to 3.2, and from 1.4 to 2.6 for 1 day, 3 days, and 5 days, respectively. For total-day sedentary behavior, the SEMs were calculated for 1-9 days. The SEMs ranged from 1.7 to 2.8, from 1.0 to 1.8 , and from 0.9 to 1.5 for 1 day, 6 days, and 9 days, respectively.

\section{Discussion}

This is the first study to determine the number of days of accelerometry needed to reliably measure sedentary behavior in preschool children. We found that the reliability of accelerometry-derived sedentary behavior varied when three age-specific sedentary behavior cutpoints were applied. Our results suggest that, to achieve a reliability of $0.8,2-4$ days of monitoring are required to reliably measure in-school sedentary behavior, and 6-9 days of monitoring are required to reliably measure total day sedentary behavior in preschool children. The observed differences in the number of days needed to reliably measure sedentary behavior possibly attributed to different estimates of sedentary behavior across three different cutpoints. These findings have important implications for the measurement of sedentary behavior in preschool children using accelerometry.

A unique aspect of this study was that the reliability of accelerometry for measuring sedentary behavior was assessed separately for in-school and total day sedentary behavior. To our knowledge, only one previous study has determined the reliability of accelerometery for measuring children's MVPA at specific times during the day (e.g., pre-, during-, and after school hours) [35], and no study has determined the reliability of accelerometry for measuring sedentary behavior. Estimating the specific reliability of in-school sedentary behavior is important because interventions designed to reduce sedentary behavior are often childcare center- or preschool-based [51-55], and researchers need a reliable measure to quantify their outcome of interest. Our results showed that in-school sedentary behavior was more stable than total-day sedentary behavior across days of the week, as evidenced by higher ICCs and the lower number of days required to achieve $80 \%$ reliability for in-school sedentary behavior compared to total day sedentary behavior.

We found that time spent in total-day sedentary behavior was significantly lower on weekend days compared to weekdays. This indicates that there was greater within-individual (day-to-day) variability 
in total-day sedentary behavior compared to in-school sedentary behavior [56,57]. By including the after-school hours and weekend data in total sedentary behavior, the within-individual variability of total-day sedentary behavior could be greater than that of in-school sedentary behavior. When we tested this hypothesis using our data, we observed the greater within-individual variability in total-day sedentary behavior compared to in-school sedentary behavior (data not shown). Therefore, the observed greater number of days of monitoring to achieve the desired reliability for total day sedentary behavior compared to in-school sedentary behavior is likely due to the greater within-individual variability in total day sedentary behavior.

It is also important to discuss our finding regarding the markedly longer monitoring period (14-19 days across different cutpoints) required to achieve $\geq 90 \%$ reliability for total day sedentary behavior. The formula used to estimate the ICCs is the function of between- and within-individual variability. As indicated by the low between-individual variability in our sample of preschool children, the ICCs for total-day sedentary behavior may be underestimated, which resulted in an overestimation of the number of days required to reliably measure sedentary behavior. Supporting this, the standard deviation and the coefficient of variance $(\mathrm{CoV})$ were lower for total day sedentary behavior compared to in-school sedentary behavior (Table 2), suggesting the distribution of time spent in total sedentary behavior was more homogeneous than in-school sedentary behavior.

In addition to the reliability estimates observed in this study, we also presented the precision of the accelerometry-derived sedentary behavior using SEM. Unlike the observed reliabilities, the precision determined by SEMs was greater (i.e., smaller SEM) for total-day compared to in-school sedentary behavior. This was due to the smaller standard deviation for total-day sedentary behavior as opposed to in-school sedentary behavior. Between different cutpoints, moreover, the precision determined by SEMs was not consistent with the reliability determined by ICCs. The disagreement between observed reliability (ICCs) and precision (SEMs) implies that understanding the reliability and precision of measurement of sedentary behavior is complex, and there is no single gold-standard statistical method to determine the number of days needed to reliably measure sedentary behavior. Nonetheless, both estimated ICCs and SEMs suggest that 2-4 days and 6-9 days of accelerometry monitoring provides a reliable and precise measure for in-school (ICCs $\geq 0.8$; SEMs range: 1.5-3.7) and total-day sedentary behavior (ICCs $\geq 0.8$; SEMs range: 0.9-1.8), respectively.

These findings have important implications for both practitioners and researchers in public health. Based on our findings, two days of sedentary behavior monitoring may be acceptable for practitioners who use accelerometry to screen levels of preschooler's sedentary behavior in childcare centers or preschools. A two-day monitoring reduces overall surveillance burden, such as time, costs, and technical expertise in comparison to five days of monitoring. From a research standpoint, however, selecting a protocol comparable with existing studies for comparative purposes and study resources needs to be considered in selecting the number of days of measurement.

This study had several strengths, including the use of the most widely-validated accelerometers to measure sedentary behavior in preschool children [32,40-42]. Finding of this study are applicable to studies using different models of ActiGraph accelerometers because there is no inter-model differences in activity counts data [58,59]. This study also included the largest sample of preschool children among studies that have examined the reliability of accelerometry for the measurement of sedentary behavior in preschool children $[36,60]$. The sample for this study, which consisted of subsamples of a voluntary 
sample of preschool children, may limit the generalizability of the findings of this study. Future research including different samples of preschool children should be explored to confirm the findings of this study.

\section{Conclusions}

In conclusion, depending upon the sedentary behavior cutpoints, two to four days and six to nine days of accelerometry monitoring are required to reliably measure in-school and total-day sedentary behavior, respectively, in preschool children. Overall, fewer days of accelerometry monitoring are required to reliably measure in-school sedentary behavior compared to total-day sedentary behavior. The greatest reliability, and hence the lowest number of days, to reliably measure accelerometry-derived sedentary behavior, was obtained using the cutpoints of $<200 \mathrm{cts} / 15 \mathrm{~s}$ for in-school sedentary behavior (two days), and $<373 \mathrm{cts} / 15 \mathrm{~s}$ for total-day sedentary behavior (six days), respectively. These findings provide important guidance for the design of research in which accelerometry will be used to measure sedentary behavior in preschool children. In addition, knowing the reliability of accelerometry in measuring sedentary behavior will ultimately contribute to research designed to monitor and reduce population levels of sedentary behavior.

\section{Acknowledgments}

Supported by National Institute of Child Health and Human Development grants R01HD043125. We thank all participants, parents, and preschools that participated in this investigation and Steven N. Blair and Jihong Liu for editorial assistance in the preparation of the manuscript. We have disclosed that there are no financial or other relationships that might lead to a conflict of interest from any author.

\section{Author Contributions}

All authors contributed extensively to the work presented in this article. Wonwoo Byun designed the study, undertook the data analysis and interpretation, and led the writing of the manuscript. Michael W. Beets and Russell R. Pate contributed to conceptualizing the study, the data interpretation, and drafting the manuscript.

\section{Conflicts of Interest}

The authors declare no conflict of interest.

\section{References}

1. Freedman, D.S.; Khan, L.K.; Dietz, W.H.; Srinivasan, S.R.; Berenson, G.S. Relationship of childhood obesity to coronary heart disease risk factors in adulthood: The Bogalusa Heart Study. Pediatrics 2001, 108, 712-728.

2. Liang, Y.; Hou, D.; Zhao, X.; Wang, L.; Hu, Y.; Liu, J.; Cheng, H.; Yang, P.; Shan, X.; Yan, Y.; et al. Childhood obesity affects adult metabolic syndrome and diabetes. Endocrine 2015, 50, 87-92. 
3. Morrison, J.A.; Friedman, L.A.; Wang, P.; Glueck, C.J. Metabolic syndrome in childhood predicts adult metabolic syndrome and type 2 diabetes mellitus 25 to 30 years later. J. Pediatr. 2008, 152, 201-206.

4. Srinivasan, S.R.; Myers, L.; Berenson, G.S. Predictability of childhood adiposity and insulin for developing insulin resistance syndrome (syndrome X) in young adulthood: The Bogalusa Heart Study. Diabetes 2002, 51, 204-209.

5. Skinner, A.C.; Skelton, J.A. Prevalence and trends in obesity and severe obesity among children in the United States, 1999-2012. JAMA Pediatr. 2014, 168, 561-566.

6. Ogden, C.L.; Carroll, M.D.; Kit, B.K.; Flegal, K.M. Prevalence of childhood and adult obesity in the United States, 2011-2012. JAMA 2014, 311, 806-814.

7. Lloyd, L.J.; Langley-Evans, S.C.; McMullen, S. Childhood obesity and risk of the adult metabolic syndrome: A systematic review. Int. J. Obes. 2012, 36, 1-11.

8. McMullen, S. Childhood obesity: The impact on long-term risk of metabolic and CVD is not necessarily inevitable. Proc. Nutr. Soc. 2014, 73, 389-396.

9. Serdula, M.K.; Ivery, D.; Coates, R.J.; Freedman, D.S.; Williamson, D.F.; Byers, T. Do obese children become obese adults? A review of the literature. Prev. Med. 1993, 22, 167-177.

10. Singh, A.S.; Mulder, C.; Twisk, J.W.; van Mechelen, W.; Chinapaw, M.J. Tracking of childhood overweight into adulthood: A systematic review of the literature. Obes. Rev.: Off. J. Int. Assoc.Study Obes. 2008, 9, 474-488.

11. Pate, R.R.; O’Neill, J.R.; Brown, W.H.; Pfeiffer, K.A.; Dowda, M.; Addy, C.L. Prevalence of Compliance with a New Physical Activity Guideline for Preschool-Age Children. Child. Obes. 2015, 11, 415-420.

12. Byun, W.; Blair, S.N.; Pate, R.R. Objectively measured sedentary behavior in preschool children: Comparison between Montessori and traditional preschools. Int. J. Behav. Nutr. Phys. Act. 2013, 10, doi:10.1186/1479-5868-10-2.

13. Vanderloo, L.M.; Tucker, P. Weekly trends in preschoolers' physical activity and sedentary time in childcare. Int. J. Environ. Res. Public Health 2015, 12, 2454-2464.

14. Vanderloo, L.M.; Tucker, P.; Johnson, A.M.; van Zandvoort, M.M.; Burke, S.M.; Irwin, J.D. The influence of centre-based childcare on preschoolers' physical activity levels: A cross-sectional study. Int. J. Environ. Res. Public Health 2014, 11, 1794-1802.

15. Jago, R.; Thompson, J.L.; Sebire, S.J.; Wood, L.; Pool, L.; Zahra, J.; Lawlor, D.A. Cross-sectional associations between the screen-time of parents and young children: Differences by parent and child gender and day of the week. Int. J. Behav. Nutr. Phys. Act. 2014, 11, doi:10.1186/1479-5868-11-54.

16. Byun, W.; Liu, J.; Pate, R.R. Association between objectively measured sedentary behavior and body mass index in preschool children. Int. J. Obes. 2013, 37, 961-965.

17. American Academy of Pediatrics. Committee on Public Education. American Academy of Pediatrics: Children, adolescents, and television. Pediatrics 2001, 107, 423-426.

18. Institute of Medicine. Early Childhood Obesity Prevention Policies: Goals, Recommendations, and Potential Actions. 23 June 2011. Available online: https://iom.nationalacademies.org/ (accessed on 7 July 2015).

19. Herman, K.M.; Sabiston, C.M.; Mathieu, M.E.; Tremblay, A.; Paradis, G. Sedentary behavior in a cohort of 8- to 10-year-old children at elevated risk of obesity. Prev. Med. 2014, 60, 115-120. 
20. Jackson, D.M.; Djafarian, K.; Stewart, J.; Speakman, J.R. Increased television viewing is associated with elevated body fatness but not with lower total energy expenditure in children. Am. J. Clin. Nutr. 2009, 89, 1031-1036.

21. Pratt, C.; Webber, L.S.; Baggett, C.D.; Ward, D.; Pate, R.R.; Murray, D.; Lohman, T.; Lytle, L.; Elder, J.P. Sedentary activity and body composition of middle school girls: The trial of activity for adolescent girls. Res. Q. Exerc. Sport 2008, 79, 458-467.

22. Mitchell, J.A.; Mattocks, C.; Ness, A.R.; Leary, S.D.; Pate, R.R.; Dowda, M.; Blair, S.N.; Riddoch, C. Sedentary behavior and obesity in a large cohort of children. Obesity 2009, 17, 1596-1602.

23. Mitchell, J.A.; Rodriguez, D.; Schmitz, K.H.; Audrain-McGovern, J. Greater screen time is associated with adolescent obesity: A longitudinal study of the BMI distribution from Ages 14 to 18. Obesity 2013, 21, 572-575.

24. Peart, T.; Velasco Mondragon, H.E.; Rohm-Young, D.; Bronner, Y.; Hossain, M.B. Weight status in US youth: The role of activity, diet, and sedentary behaviors. Am. J. Health Behav. 2011, 35, 756-764.

25. Mitchell, J.A.; Pate, R.R.; Blair, S.N. Screen-based sedentary behavior and cardiorespiratory fitness from age 11 to 13. Med. Sci. Sports Exerc. 2012, 44, 1302-1309.

26. Mota, J.; Ribeiro, J.C.; Carvalho, J.; Santos, M.P.; Martins, J. Television viewing and changes in body mass index and cardiorespiratory fitness over a two-year period in schoolchildren. Pediatr. Exerc. Sci. 2010, 22, 245-253.

27. Martinez-Gomez, D.; Ortega, F.B.; Ruiz, J.R.; Vicente-Rodriguez, G.; Veiga, O.L.; Widhalm, K.; Manios, Y.; Beghin, L.; Valtuena, J.; Kafatos, A.; et al. Excessive sedentary time and low cardiorespiratory fitness in European adolescents: The HELENA study. Arch. Dis. Child. 2011, 96, 240-246.

28. Hardy, L.L.; Denney-Wilson, E.; Thrift, A.P.; Okely, A.D.; Baur, L.A. Screen time and metabolic risk factors among adolescents. Arch. Pediatr. Adolesc. Med. 2010, 164, 643-649.

29. Sardinha, L.B.; Andersen, L.B.; Anderssen, S.A.; Quiterio, A.L.; Ornelas, R.; Froberg, K.; Riddoch, C.J.; Ekelund, U. Objectively measured time spent sedentary is associated with insulin resistance independent of overall and central body fat in 9- to 10-year-old Portuguese children. Diabetes Care 2008, 31, 569-575.

30. Hancox, R.J.; Milne, B.J.; Poulton, R. Association between child and adolescent television viewing and adult health: A longitudinal birth cohort study. Lancet 2004, 364, 257-262.

31. Erik Landhuis, C.; Poulton, R.; Welch, D.; Hancox, R.J. Programming obesity and poor fitness: The long-term impact of childhood television. Obesity 2008, 16, 1457-1459.

32. Reilly, J.J.; Coyle, J.; Kelly, L.; Burke, G.; Grant, S.; Paton, J.Y. An objective method for measurement of sedentary behavior in 3- to 4-year olds. Obes. Res. 2003, 11, 1155-1158.

33. Sirard, J.R.; Pate, R.R. Physical activity assessment in children and adolescents. Sports Med. 2001, 31, 439-454.

34. Basterfield, L.; Adamson, A.J.; Pearce, M.S.; Reilly, J.J. Stability of habitual physical activity and sedentary behavior monitoring by accelerometry in 6- to 8-year-olds. J. Phys. Act. Health 2011, 8, 543-547.

35. Fairclough, S.J.; Butcher, Z.H.; Stratton, G. Whole-day and segmented-day physical activity variability of northwest England school children. Prev. Med. 2007, 44, 421-425. 
36. Penpraze, V.; Reilly, J.J.; MacLean, C.M.; Montgomery, C.; Kelly, L.A.; Paton, J.Y.; Aitchison, T.; Grant, S. Monitoring of physical activity in young children: How much is enough? Pediatric Exerc. Sci. 2006, 18, 483-491.

37. Sigmund, E.; de Ste Croix, M.; Miklankova, L.; Fromel, K. Physical activity patterns of kindergarten children in comparison to teenagers and young adults. Eur. J. Public Health 2007, 17, 646-651.

38. Addy, C.L.; Trilk, J.L.; Dowda, M.; Byun, W.; Pate, R.R. Assessing preschool children's physical activity: How many days of accelerometry measurement. Pediatr. Exerc. Sci. 2014, 26, 103-109.

39. Evenson, K.R.; Catellier, D.J.; Gill, K.; Ondrak, K.S.; McMurray, R.G. Calibration of two objective measures of physical activity for children. J. Sports Sci. 2008, 26, 1557-1565.

40. Pate, R.R.; Almeida, M.J.; McIver, K.L.; Pfeiffer, K.A.; Dowda, M. Validation and calibration of an accelerometer in preschool children. Obesity 2006, 14, 2000-2006.

41. Sirard, J.R.; Trost, S.G.; Pfeiffer, K.A.; Dowda, M.; Pate, R.R. Calibration and evaluation of an objective measure of physical activity in preschool children. J. Phys. Act. Health 2005, 2, 345-357.

42. Van Cauwenberghe, E.; Labarque, V.; Trost, S.G.; de Bourdeaudhuij, I.; Cardon, G. Calibration and comparison of accelerometer cut points in preschool children. Int. J. Pediatr. Obes. 2011, 6, $582-589$.

43. Dowda, M.; Pfeiffer, K.A.; Brown, W.H.; Mitchell, J.A.; Byun, W.; Pate, R.R. Parental and environmental correlates of physical activity of children attending preschool. Arch. Pediatr. Adolesc. Med. 2011, 165, 939-944.

44. Colley, R.C.; Garriguet, D.; Adamo, K.B.; Carson, V.; Janssen, I.; Timmons, B.W.; Tremblay, M.S. Physical activity and sedentary behavior during the early years in Canada: A cross-sectional study. Int. J. Behav. Nutr. Phys. Act. 2013, 10, doi:10.1186/1479-5868-10-54.

45. Pate, R.R.; O’Neill, J.R.; Byun, W.; McIver, K.L.; Dowda, M.; Brown, W.H. Physical activity in preschool children: Comparison between Montessori and traditional preschools. J. Sch. Health 2014, 84, 716-721.

46. Vanderloo, L.M.; D’Alimonte, N.A.; Proudfoot, N.A.; Tucker, P.; Timmons, B.W. Comparing the Actical and ActiGraph Approach to Measuring Young Children's Physical Activity Levels and Sedentary Time. Pediatr. Exerc. Sci. 2015, doi:10.1123/pes.2014-0218.

47. Tudor-Locke, C.; Burkett, L.; Reis, J.P.; Ainsworth, B.E.; Macera, C.A.; Wilson, D.K. How many days of pedometer monitoring predict weekly physical activity in adults? Prev. Med. 2005, 40, 293-298.

48. Safrit, M.J.; Wood, T.M. Measurement Concepts in Physical Education and Exercise Science; Human Kinetics: Champaign, IL, USA, 1989.

49. Baranowski, T.; Masse, L.C.; Ragan, B.; Welk, G. How many days was that? We're still not sure, but we're asking the question better! Med. Sci. Sports Exerc. 2008, 40, S544-S549.

50. Morrow, J., Jr.; Jackson, A.; Disch, J. Measurement and Evaluation in Human Performsance; Human Kinetics: Champaign, IL, USA, 2010; Volume 4.

51. Reilly, J.J.; Kelly, L.; Montgomery, C.; Williamson, A.; Fisher, A.; McColl, J.H.; Lo Conte, R.; Paton, J.Y.; Grant, S. Physical activity to prevent obesity in young children: Cluster randomised controlled trial. BMJ 2006, 333, doi:10.1136/bmj.38979.623773.55. 
52. O’Dwyer, M.V.; Fairclough, S.J.; Ridgers, N.D.; Knowles, Z.R.; Foweather, L.; Stratton, G. Effect of a school-based active play intervention on sedentary time and physical activity in preschool children. Health Educ. Res. 2013, 28, 931-942.

53. Hannon, J.C.; Brown, B.B. Increasing preschoolers' physical activity intensities: An activity-friendly preschool playground intervention. Prev. Med. 2008, 46, 532-536.

54. De Craemer, M.; de Decker, E.; Verloigne, M.; de Bourdeaudhuij, I.; Manios, Y.; Cardon, G.; ToyBox-study Group. The effect of a kindergarten-based, family-involved intervention on objectively measured physical activity in Belgian preschool boys and girls of high and low SES: The ToyBox-study. Int. J. Behav. Nutr. Phys. Act. 2014, 11, doi:10.1186/1479-5868-11-38.

55. Pfeiffer, K.A.; Saunders, R.P.; Brown, W.H.; Dowda, M.; Addy, C.L.; Pate, R.R. Study of Health and Activity in Preschool Environments (SHAPES): Study protocol for a randomized trial evaluating a multi-component physical activity intervention in preschool children. BMC Public Health 2013, 13, doi:10.1186/1471-2458-13-728.

56. Gretebeck, R.J.; Montoye, H.J. Variability of some objective measures of physical activity. Med. Sci. Sports Exerc. 1992, 24, 1167-1172.

57. Trost, S.G.; Pate, R.R.; Freedson, P.S.; Sallis, J.F.; Taylor, W.C. Using objective physical activity measures with youth: How many days of monitoring are needed? Med. Sci. Sports Exerc. 2000, 32, 426-431.

58. John, D.; Tyo, B.; Bassett, D.R. Comparison of four ActiGraph accelerometers during walking and running. Med. Sci. Sports Exerc. 2010, 42, 368-374.

59. Sasaki, J.E.; John, D.; Freedson, P.S. Validation and comparison of ActiGraph activity monitors. J. Sci. Med. Sport 2011, 14, 411-416.

60. Toschke, J.A.; von Kries, R.; Rosenfeld, E.; Toschke, A.M. Reliability of physical activity measures from accelerometry among preschoolers in free-living conditions. Clin. Nutr. 2007, 26, 416-420.

(C) 2015 by the authors; licensee MDPI, Basel, Switzerland. This article is an open access article distributed under the terms and conditions of the Creative Commons Attribution license (http://creativecommons.org/licenses/by/4.0/). 